\title{
A successful lung transplant from a 3-year-old donor after controlled cardiac death followed by ex vivo lung perfusion: A case report
}

\author{
Marcos Galasso, MD, ${ }^{a}$ Rachel D. Vanderlaan, MD, PhD, ${ }^{b}$ Melinda Solomon, MD, MSc, ${ }^{c}$ \\ Christopher Caldarone, MD ${ }^{\mathrm{c}}$ Shaf Keshavjee, MD, MsC, ${ }^{\mathrm{a}, \mathrm{d}}$ Marcelo Cypel, MD, MSc, ${ }^{\mathrm{a}, \mathrm{d}}$ and \\ Marc de Perrot, MD, MSc, ${ }^{\text {a,d }}$ Toronto, Ontario, Canada
}

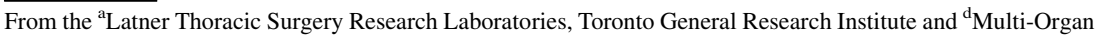
Transplant Program, University Health Network, Toronto, Ontario, Canada; ${ }^{b}$ Division of Cardiac Surgery, University of Toronto, Toronto, Ontario, Canada; and ${ }^{\mathrm{c}}$ Transplant and Regenerative Medicine Centre, The Hospital for Sick Children, Toronto, Ontario, Canada.

Disclosures: M.C. and S.K. are founders of XOR Labs Toronto and consultants for Lung Bioengineering. All other authors have nothing to disclose with regard to commercial support.

Received for publication Feb 8, 2019; accepted for publication Feb 12, 2019; available ahead of print May 21, 2019.

Address for reprints: Marcos Galasso, MD, Latner Thoracic Surgery Research Laboratories, University Health Network, 101 College St, 2nd Floor (2-818) Toronto, ON, Canada M5G 1L7 (E-mail: Marcos.Galasso@ uhn.ca).

J Thorac Cardiovasc Surg 2019;158:e149-52 0022-5223/ $\$ 36.00$

Crown Copyright $@ 2019$ Published by Elsevier Inc. on behalf of The American Association for Thoracic Surgery https://doi.org/10.1016/j.jtcvs.2019.02.131
}

A 3-year-old male patient (blood type A+) with primary pulmonary vein stenosis (PVS) was listed for transplantation because of progressive PVS involving all 4 pulmonary veins with elevated right ventricular pressures and ongoing hemoptysis (Figure 1). Initial management included 3 cardiac catheterizations with balloon dilations, followed by sutureless repair of right pulmonary veins with simultaneous workup for lung transplantation (Ltx). The patient was listed for bilateral Ltx with recurrence of aggressive restenosis 2 months after surgical intervention, and balloon dilations were performed as a bridge to transplant. After 1 month on the waiting list (11 months after initial presentation), lungs from a 3-year-old donor were offered, with donor and recipient total lung capacity, blood group, height, and weight adequately matched. The donor cause of death was anoxia after drowning, and there was concern for suspected aspiration during resuscitation. The donor chest $\mathrm{x}$ ray presented sparse consolidation areas in the right lower lobe (Figure 2, A) and an arterial blood gas of $\mathrm{pH} 7.41$; partial pressure of carbon dioxide of $40 \mathrm{~mm} \mathrm{Hg}$; partial pressure of oxygen of $233 \mathrm{~mm} \mathrm{Hg}$; and saturated oxygen of $100 \%$, with mechanical ventilation in pressure-control mode (fraction of inspired oxygen: $100 \%$; 20 respirations/min; positive end-expiratory pressure: $10 \mathrm{~cm} / \mathrm{H} 2 \mathrm{O}$ ).

Lung procurement was done after donation after cardiac death (DCD), with cardiac death declared 12 minutes after the withdrawal of life support. Because of low partial pressure of oxygen and suspicion for aspiration with heavy and atelectatic right lower lobe after the pulmonary flush, the donor lungs were placed on ex vivo lung perfusion (EVLP) for organ assessment. The total cold ischemic

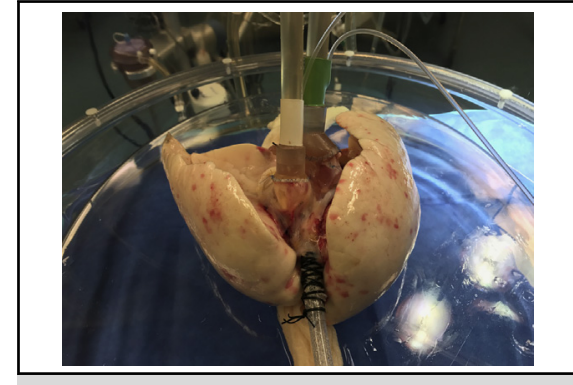

A 3-year-old donor lung during EVLP.

\section{Central Message}

We describe a successful Ltx from a 3-year-old DCD donor to a recipient with primary PVS after assessment and treatment with EVLP.

See Commentary on page e153.

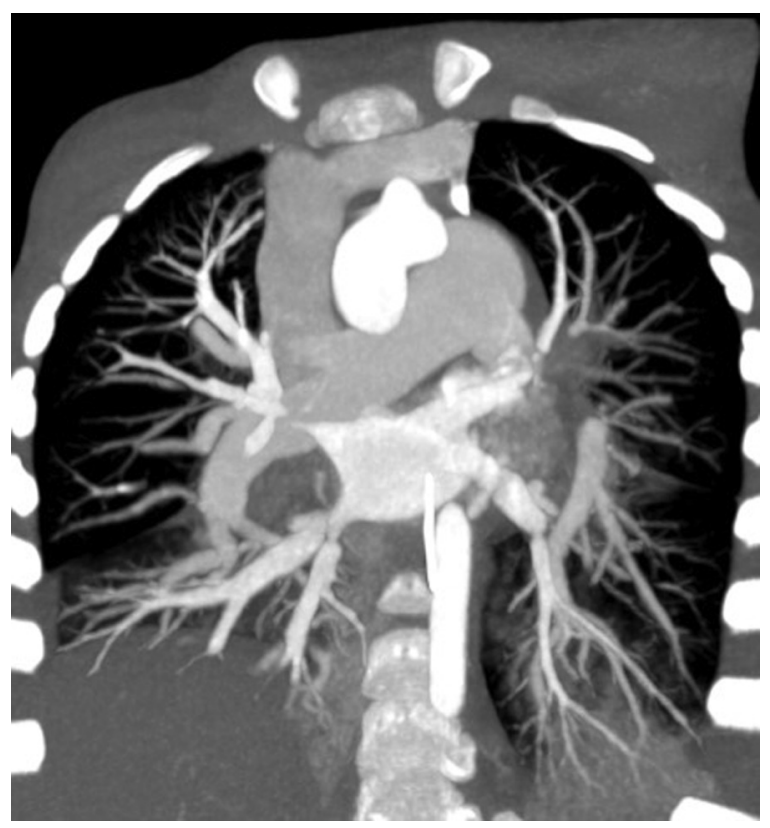

FIGURE 1. Computed tomography of the recipient 2 months before LTx. Stenosis demonstrating lack of contrast in all the main pulmonary veins. Perihilar infiltrate in lung parenchyma was also seen. 


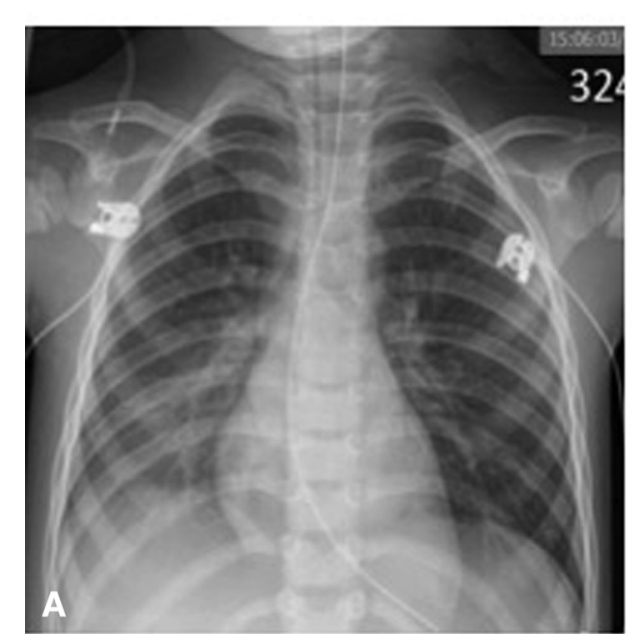

Donor

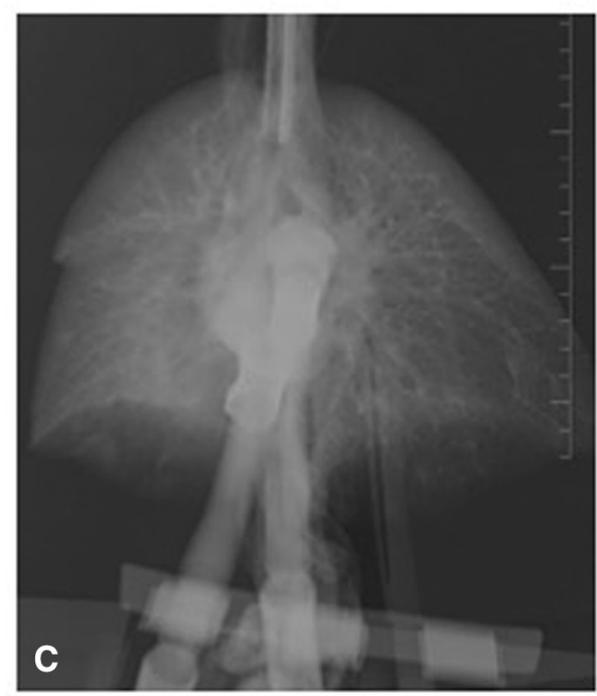

EVLP 3h

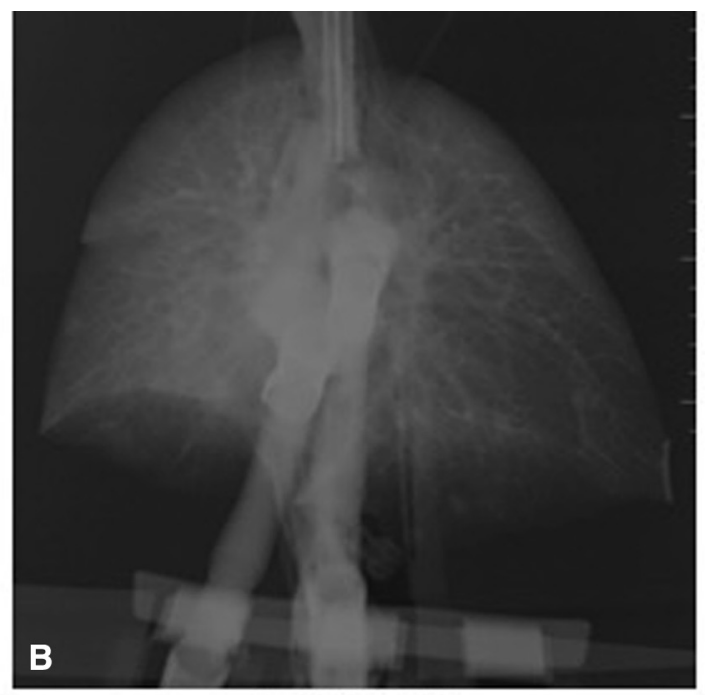

EVLP 1h

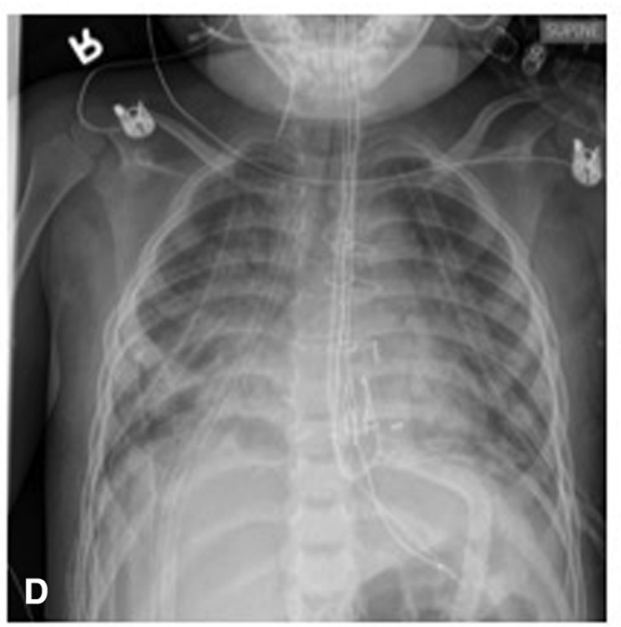

Recipient (ICU admission)

FIGURE 2. A, Donor chest X-ray before donation. Some sparse consolidation areas can be seen in the right lower lobe, suggesting aspiration. B, During the first hour of EVLP, the right lung demonstrated some edematous area, particularly in the right lower lobe. C, Despite stable or improving physiologic parameters, similar findings were observed on x-ray after 3 hours of EVLP. D, First chest X-ray of the recipient immediately after intensive care unit admission after double LTx. EVLP, Ex vivo lung perfusion; $I C U$, intensive care unit.

time was 200 minutes, and the total time on EVLP was 4 hours (Figure 3). The actual donor body weight was used for EVLP flow rate calculation instead of the ideal body weight, currently used for adult donors. During EVLP, lungs presented some areas of consolidation on the first and third x-ray assessments (Figure 2, $B$ and $C$ ). Stable airway pressures (peak, mean, and plateau) were observed during EVLP, as well as good lung compliances (static and dynamic), low pulmonary vein resistance, and increasing $\mathrm{P} / \mathrm{F}$ ratio (Figure $4, A-D$ ). Perfusate $\mathrm{pH}$ presented results in the acceptable range, with moderate lactate increase and low glucose and perfusate solution consumption.
After 4 hours of EVLP, lungs were accepted, and the recipient underwent sequential bilateral Ltx with cardiopulmonary bypass. The aorta was crossclamped for 137 minutes, and the heart was protected with cardioplegia during the implantation of both lungs. Both right and left atrial anastomoses were performed after removing a large cuff of the recipient atrium to encompass the ostium of the upper and lower pulmonary veins. The lung function after weaning cardiopulmonary bypass was suboptimal, and the patient was transferred to the intensive care unit on nitric oxide $40 \mathrm{ppb}$ and vasoactive drugs. Pulmonary edema and right lower lobe consolidation were seen immediately after Ltx 


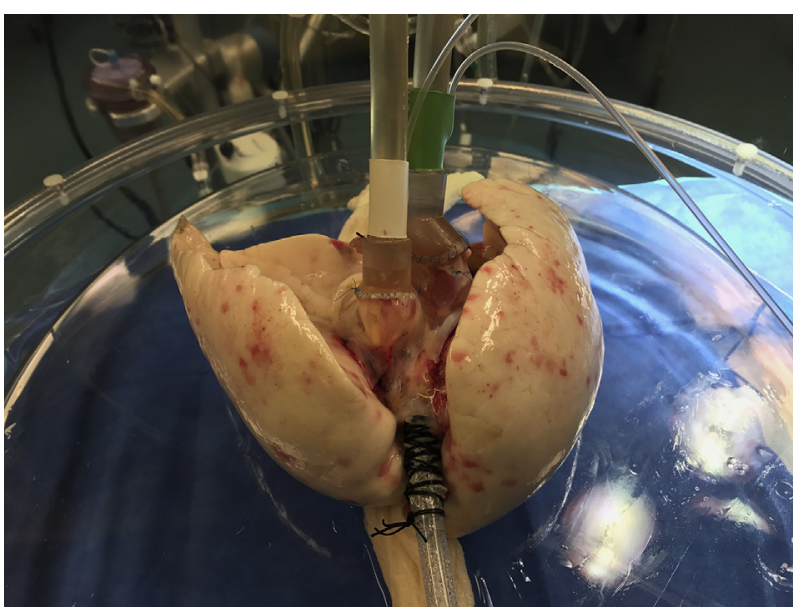

FIGURE 3. A 3-year-old donor lung during EVLP.

with a suspected sepsis adequately treated with piperacillintazobactam. The patient was weaned from nitrous oxide on postoperative day 4 and extubated on postoperative day 11 . At this point, episodic nocturnal oxygen was necessary, and a right diaphragmatic palsy was observed on ultrasound, with normal left diaphragm function. At 1 year after Ltx, he is well from a respiratory point of view, but with mild renal dysfunction requiring close immunosuppression monitoring.

Pediatric Ltx is a successful therapy for end-stage lung diseases. However, donor lung use remains low despite

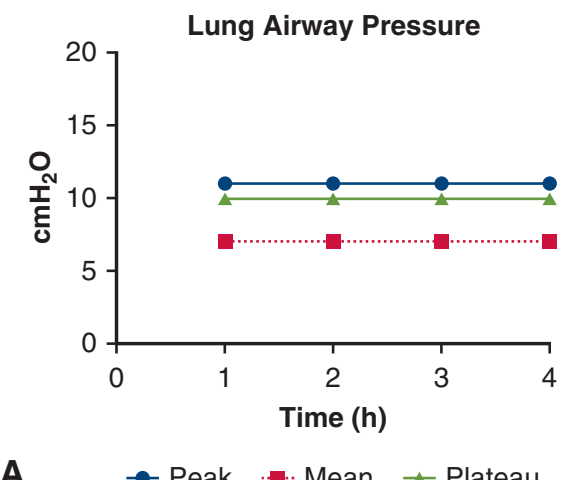

A

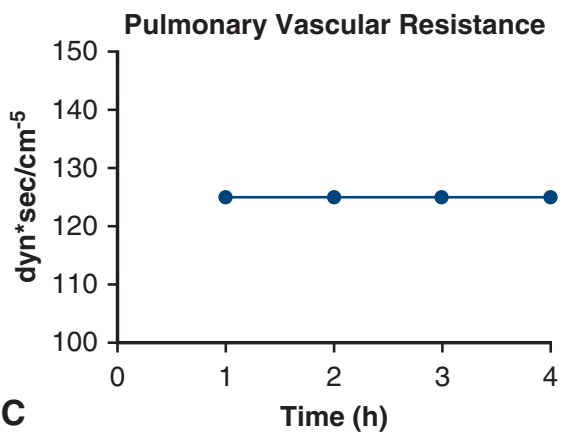

available organ donors, ${ }^{1}$ leading to considerable wait-list mortality. ${ }^{2}$ Despite the recent increase in DCD organ use, DCD donors aged less than 11 years are still rare, and pediatric Ltx is performed only in specialized centers in North America. ${ }^{3}$ Initially conceived to be used clinically to assess DCD lungs, EVLP has been successfully used to expand organ use by including otherwise declined marginal lungs to the pool, increasing the use rate. ${ }^{4}$ Progressive multivessel PVS is associated with a poor prognosis because of the development of pulmonary hypertension and right heart failure. $^{5}$

We describe a successful pediatric bilateral sequential LTx after the use of EVLP to allow for organ assessment after DCD. The recipient had primary PVS with progressive stenosis involving 4 veins with ongoing hemoptysis and right heart failure. At our institution, the multidisciplinary PVS team engaged early with the LTx program and worked to successfully bridge the child to transplant with repeated catheter-based interventions and pulmonary vein surgery. The use of EVLP to facilitate donor organ use helped to mitigate the potential high wait-list mortality and substantial morbidity that can be accrued in infants with PVS listed for transplant. ${ }^{3}$ EVLP is an important adjunct in pediatric Ltx programs, and agebased protocols will facilitate its use in pediatric donors. To the best of our knowledge, this is one of the youngest donor lungs placed on EVLP and successfully transplanted.
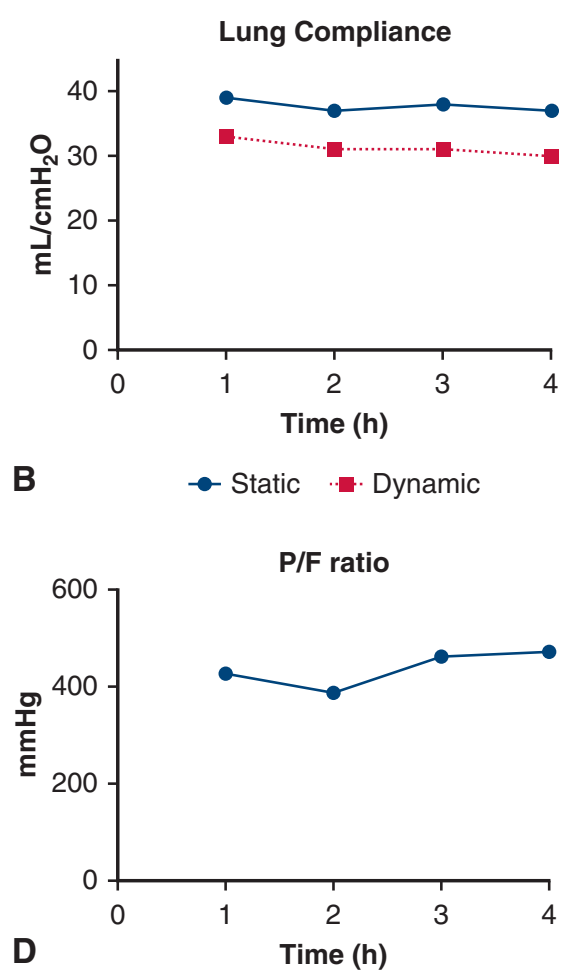

FIGURE 4. Functional parameters during EVLP, demonstrating stable airway pressures (peak, mean, and plateau) (A), lung static and dynamic compliances (B), low pulmonary vascular resistance (C), and increase in P/F ratio (D). 


\section{References}

1. Yeung JC, Keshavjee S. Overview of clinical lung transplantation. Cold Spring Harb Perspect Med. 2014;4:4a015628.

2. Goldfarb SB, Hayes D Jr, Levvey BJ, Cherikh WS, Chambers DC, Khush KK, et al. The international thoracic organ transplant registry of the International Society for Heart and Lung Transplantation: twenty-first pediatric lung and heartlung transplantation report-2018; Focus theme: multiorgan transplantation. $J$ Heart Lung Transplant. 2018;37:1196-206.
3. Luc JT, Nagendran J. The evolving potential for pediatric ex vivo lung perfusion. Pediatr Transplant. 2016;20:13-22.

4. Cypel M, Yeung JC, Liu M, Anraku M, Chen F, Karolak W, et al. Normothermic ex vivo lung perfusion in clinical lung transplantation. $N$ Engl J Med. 2011;364: $1431-40$.

5. Pazos-López P, García-Rodríguez C, Guitián-González A, Paredes-Galán E, Álvarez-Moure MÁ, Rodríguez-Álvarez M, et al. Pulmonary vein stenosis: etiology, diagnosis and management. World J Cardiol. 2016;8:81-8. 